Arqueología y Sociedad,

$N^{o} 16,2005$

\title{
Comentarios sobre la Palinología del sitio de Pacopampa, Perú*
}

Robert R. Kautzz

Durante las discusiones que en noviembre de 1972 sostuvimos con la Dra. Rosa Fung Pineda, del Museo de Arqueología y Etnología de la Universidad Nacional Mayor de San Marcos, muy gentilmente me ofreció muestras con polen del período Chavín, que ella anteriormente había extraído del sitio de Pacopampa, Perú. Los siguientes resultados de este análisis, si bien son desalentadores en cuanto a los particulares, hacen notar que científicos tan lúcidos como la Dra. Fung pueden, en un futuro cercano, resolver muchos de los interrogantes del paleoambiente que actualmente abruman a los arqueólogos que quieren estudiar al hombre prehistórico peruano dentro del medio ambiente en el cual se desenvolvió.

\section{Procedimientos de Laboratorio}

La extracción del polen se hizo siguiendo los procedimientos delineados en Mehringer (1967:136-137) con la adición de acetolisis, destinada a quitar la celulosa excedente (Faegri e Iverson 1964:71).El polen fue colocado en placas de vidrio, coloreado y analizado por un microscopio (440 x) en forma sistemática y no superpuesta. Con la excepción de la muestra 6 , todas las placas fueron doblemente analizadas en un intento estéril por obtener estadísticamente resultados más positivos.

\section{Discusión}

Debido tanto a la preservación diferencial del polen como, al menos un caso, de dispersión estratigráfica, los resultados del análisis de polen para Pacopampa tienen un valor analítico muy limitado.

Las muestras del 1 al 5 cuando fueron sumergidas en ácido clorhídrico reaccionaron violentamente. Junto con la apariencia de la matriz del suelo (terrones de material granuoso y ligeramente coloreado), se anticipó que el calcio o algún otro carbonato estaría presente, y que éste selectivamente habría destruido el polen. El logro muy limitado de esas muestras confirmó esta hipótesis precoz; por cuanto un coloramiento diferencial y la presencia de polen fósil de diferentes edades en la muestra 8 indicaba la posibilidad de un disturbamiento estratigráfico.

Aun con las limitaciones antes expuestas se pueden adelantar algunas conclusiones:

1. La muestra 6 nos proporciona una pauta (aunque no en sentido relativo) referente a las clases de vegetación que estuvieron presentes durante la ocupación humana de Pacopampa. El alto porcentaje de esporas (27\%) en la muestra 6 indica una pequeña proporción de destrucción diferencial del polen.

2. En la muestra 2 la ocurrencia de un grano de polen perteneciente a las grandes gramíneas, con la correspondiente gran abertura, señala la presencia de Zea mays, durante este período; mientras que la ocurrencia en forma esporádica de especies Typha (estera, cestería, etc.), Solanaceae (Tubérculos), un grupo de polen de hierbas, polen de Cheno-am y Malvaceae (algodón) también puede indicar la utilización cultural de la vegetación (Towle 1961).

3. La presente investigación señala que el análisis de polen debe ser intentado por los arqueólogos que trabajan en los Andes de Sudamérica cuantas veces sea posible.

Otra investigación (Schoenwetter 1972, Hurt et al.) indica igualmente el potencial que ofrece a quienes están interesados en variables tecnomedioambientales, y cómo estas se relacionan con la adaptación prehistórica.

* Publicado originalmente en la Revista del Museo Nacional, t. XLI, pp. 208-210, Lima, 1975. 
Cuadro 1

Espectros del polen de Pacopampa

$\begin{array}{lcl}\text { Muestra 1 } & \text { (Cuadro J, Capa 1)* } \\ \text { Polypodiaceae } & 1 & (3 \%) \\ \text { Trilete spores } & 6 & (18 \%) \\ \text { Graminea } & 10 & (30 \%) * * \\ \text { Glencheniaceae } & 2 & (6 \%) \\ \text { Cheno-am } & 1 & (3 \%) \\ \text { Monimiaceae } & 12 & (36 \%) \\ \text { Desconocido } & 1 & (3 \%) \\ \text { Total de granos: 33 } & \\ \text { *Esta lista se refiere solo a las formas no-trilete } \\ \text { **Contiene un gruo de 5 (no-Zea) }\end{array}$

Muestra 2 (Cuadro J, Capa 2)

$\begin{array}{lll}\text { Polypodiaceae } & 7 & (22 \%)\end{array}$

Trilete spores $\quad 6 \quad(19 \%)$

Graminea $\quad 5$ (16\%)

Glencheniaceae $\quad 1 \quad(3 \%)$

Monimiaceae $\quad 8 \quad(25 \%)$

Desconocido 3 (9\%)

Typhasp 1 (3\%)*

Large grass $\quad 1 \quad(3 \%)$

Total de granos: 32

* Posiblemente Zea.

Muestra 3 (Cuadro J, Capa 3)

Trilete spores $\quad 2 \quad(22 \%)$

Graminea $\quad 1 \quad(11 \%)$

Monimiaceae 3 (33\%)

Desconocido 1 (11\%)

High-spine Compositae 1 (11\%)

Cruciferae $\quad 1 \quad(11 \%)$

Total de granos: 9

Muestra 4 (Cuadro J, Capa 5)

Polypodiaceae 3 (12\%)

Trilete spores $\quad 8 \quad(32 \%)$

Glencheniaceae 6 (24\%)

High-spine Compositae 5 (20\%)

Solanaceae $\quad 2 \quad(8 \%)$

Verbena $\quad 1$ (4\%)

Total de granos: 25

Muestra 5 (Cuadro J, Capa 6)

Polypodiaceae $\quad 1 \quad(5 \%)$

Trilete spores $\quad 2 \quad(9 \%)$

Graminea $\quad 6 \quad(27 \%)$

Monimiaceae $\quad 5 \quad(23 \%)$ $\begin{array}{lrc}\text { Desconocido } & 2 & (9 \%) \\ \text { High-spine Compositae 1 } & (5 \%) \\ \text { Low-spine Compositae } & 2 & (9 \%) \\ \text { Solanaceae } & 1 & (5 \%) \\ \text { Rosa } & 2 & (9 \%) \\ \text { Total de granos: 22 } & & \end{array}$

Muestra 6 (Cuadro J, Capa 8)

Polypodiaceae $\quad 10 \quad(5 \%)$

Trilete spores $\quad 16 \quad(7 \%)$

Graminea $\quad 47$ (21\%)

Glencheniaceae $\quad 24$ (11\%)

Cheno-am $\quad 13$ (6\%)

Monimiaceae $\quad 7 \quad(3 \%)$

Desconocido $6 \quad(3 \%)$

Typhasp. $\quad 4 \quad(2 \%)$

Solanaceae $\quad 4 \quad(2 \%)$

Verbena $1 \quad(-1 \%)$

High-spine Compositae 44 (20\%)

Low-spine Compositae 9 (4\%)

Acacia $\quad 6 \quad(3 \%)$

Malvaceae $\quad 4 \quad(2 \%)$

Cyperaceae $\quad 5 \quad(2 \%)$

Cruciferae $\quad 8 \quad(4 \%)$

Umbellicefereae $\quad 4 \quad(2 \%)$

Lycopodium $\quad 9$ (4\%)

Total de granos: 221

Muestra 7 (Cuadro P,Capa 1)

$\begin{array}{lll}\text { Polydiaceae } & 1 & (33 \%)\end{array}$

Gleicheniaceae $\quad 1 \quad$ (33\%)

Graminea 1 (33\%)

Total de granos: 3

Muestra 8 (Cuadro P,Capa S)

$\begin{array}{lcl}\text { Polypodiaceae } & 4 & (9 \%) \\ \text { Trilete spores } & 12 & (27 \%) \\ \text { Graminea } & 7 & (16 \%) \\ \text { Glencheniaceae } & 7 & (16 \%) \\ \text { Monimiaceae } & 4 & (9 \%) \\ \text { Desconocido } & 2 & (5 \%) \\ \text { Rosa } & 1 & (2 \%) \\ \text { Malvacea } & 1 & (2 \%) \\ \text { Cruciferae } & 1 & (2 \%) \\ \text { Lycopidium } & 5 & (11 \%)^{*} \\ \text { * Posiblemente fósiles } & & \\ \text { Total de granos: } 44 & & \end{array}$

